\title{
Migrantes da construção civil em João Pessoa
}

\author{
Arivaldo J. Sezyshta* \\ Verônica Pessoa ${ }^{* *}$
}

O Serviço Pastoral dos Migrantes (SPM) e o Projeto Escola "Zé Peão" desenvolvem, em parceria, um trabalho junto aos operários da Construção Civil na capital da Paraíba, João Pessoa. Estes, em sua grande maioria, são migrantes, muitos dos quais temporários. Intencionamos relatar aqui, de forma breve, em que consiste o Projeto Escola "Zé Peão", bem como apontar para a existência de importantes redes de solidariedade detectadas entre os migrantes, as quais tecem e dão sentido às suas existências. Antes, porém, visitaremos um canteiro de obras, mergulhando na história de um personagem chamado Benedito.

Foto: Arquivo Projeto Escola Zé Peão

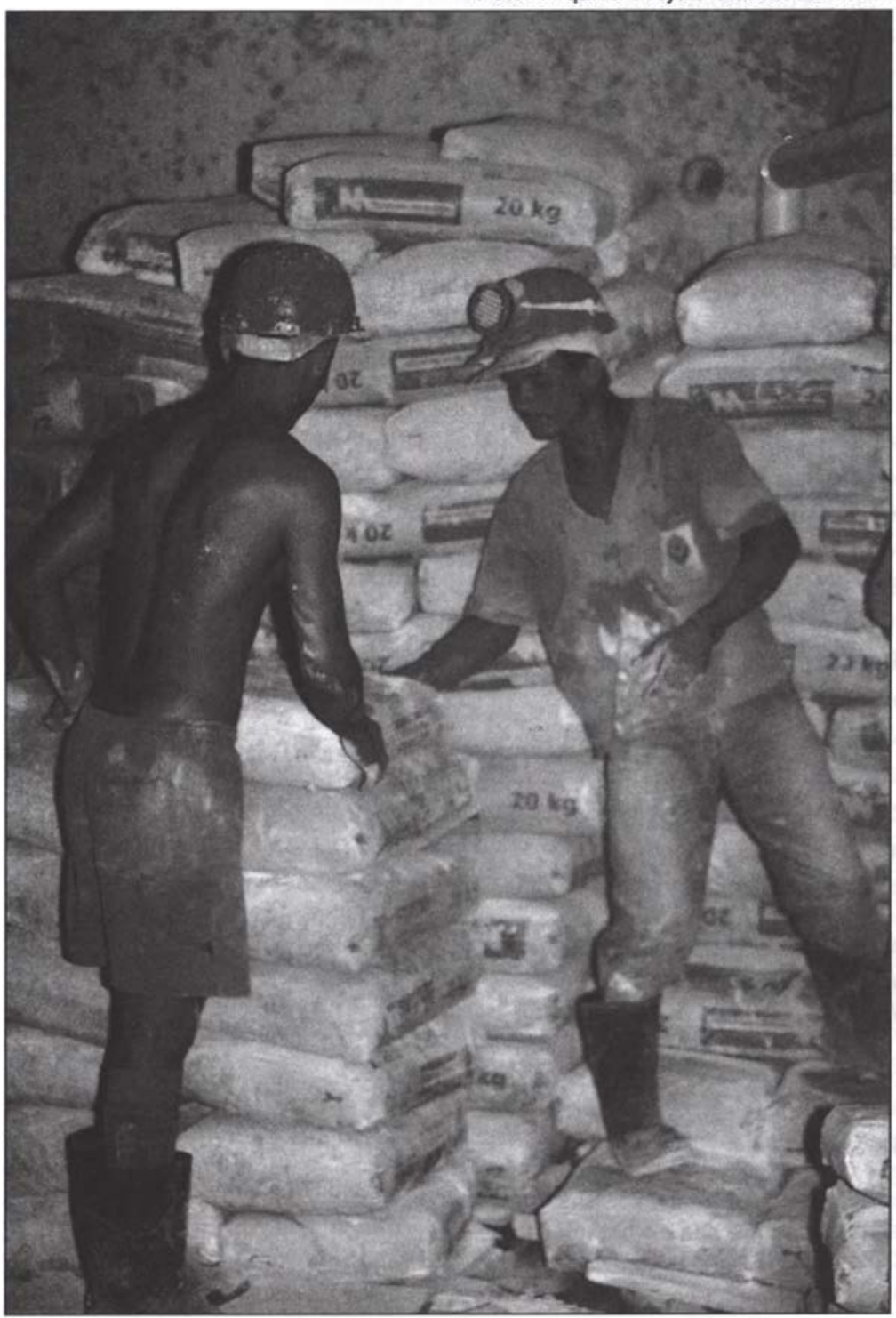

Benedito: um homem da construção ${ }^{l}$

“Meu nome é Benedito.

Sou do interior.

Moro na capital".

"No interior o trabalho era pouco",

As cercas eram muitas,

A seca era grande.

"Às vezes, trabalhava na cana.

Às vezes, trabalhava de servente.

Às vezes, fazia bico brocando mato.

Eu não tinha terra".

"Vim para a capital.

Aqui trabalho na construção civil.

Levanto edificios,

Levanto casas,

Levanto pontes e cavo galerias.

A minha mão faz a cidade maior.

Sonho construir uma boa casa.

A casa da minha família".

Aqui, não estou sozinho.

Depois de mim veio meu compadre Gino,

Meu vizinho Guido

E meu primo Miro.

Mais tarde vieram Fabiano, Zezinho e outros,

Migrantes que viraram pedreiros, pintores, ajudantes.

Todos saíram atrás de mim.

Dizem que eu puxei a fila.

Aqui, dormimos na obra,

Dividimos as tarefas.

Um faz a comida,

Outro limpa o chão.

Um outro faz a feira.

Amanhã revezaremos.

E vamos levando, se escapando. 
Quando não posso viajar para o interior Um companheiro leva o dinheiro da feira de minha família.

E traz as notícias que espantam a saudade

E aquietam o espírito.

"Toda semana, trabalho de segunda a sexta.

Às vezes, preciso trabalhar até nos sábados e nos feriados.

Todo dia pego bem cedo no trabalho,

Largo ao anoitecer.

Às vezes, faço serão.

Durmo moído de cansaço".

"De noite, jogo conversa fora.

Um companheiro toca violão.

Outro conta um caso.

Outro conta os tostões.

Bate a saudade da minha casa.

Bate a saudade da minha menina.

Bate a saudade até do meu lugar".

Nessa hora, tudo fica mais difícil.

Ainda bem que os amigos estão por perto.

Com eles as dificuldades diminuem.

Neles eu confio.

Pra eles eu falo da minha saudade.

Pra eles eu falo dos meus sonhos.

Às vezes chego a chorar.

"O clac-clac do dominó anima a noite.

O jogo de palito também.

Miro sai para namorar.

Gino e Guido vão tomar uma

cachacinha".

Chega o sono,

Ajeito meu colchão,

Durmo em paz.

Levanto cedo e vou à luta.

"Trabalho por produção.

A obra pede pressa.

A massa seca rápido e faz minha mão correr.

Com a colher, assento tijolo sobre tijolo.

$O$ mestre reclama: 'Olha o tijolo

dançando, homem!'

Calado, conserto o que fiz.

A parede vai crescendo e me faz pequeno".

$O$ sol castiga.

O suor escorre pelo meu corpo.
Minhas mãos estão cheias de calo,

Mas ainda são ágeis.

$O$ prédio já está ficando alto.

Permite enxergar o mar,

Ali, próximo, depois dos coqueiros.

$O$ almoço como com alegria.

Carne-de-sol, farinha, macaxeira e feijão.

Um bom copo d'água dá a sensação de que comi mais.

Tiro um cochilo rápido.

E o trabalho recomeça

E segue em frente até a boca da noite.

Depois do trabalho tomo um banho,

Arrumo o de cumê

E vou estudar.

A sala de aula é aqui mesmo na obra.

Meus companheiros também estudam.

Alguns já lêem e escrevem cartas.

Um dia eu também chego lá.

Outro dia recomeça.

"Miro prepara o traço.

Fabiano reboca a parede.

A massa corta as mãos e os pés da gente.

Um companheiro, de rosto suado, assobia.

Outro grita lá de cima: 'E o café, pessoal?"'

"Meu companheiro pinta a parede.

A tinta na parede é bonita de dar gosto! A tinta faz beleza e me deixa tonto".

"A tinta esconde a massa.

A massa esconde o tijolo.

O tijolo ocupa o vazio.

A massa, a tinta, o tijolo escondem a minha mão.

Escondem a mão do meu companheiro pintor.

Escondem a mão do meu companheiro pedreiro.

O edifício aparece naquela rua. Alto, bonito, aprumado..."

"Não se escuta mais o zum-zum da construção".

Os companheiros já arrumaram suas sacolas.

"Junto as minhas ferramentas.

Saio dali.

Vou começar tudo de novo".

Meus companheiros também vão.

\section{A ESCOLA "ZÉ PEÃO"}

O caso de Benedito e de seus companheiros não é exceção. São quase cinco milhões de trabalhadores na construção civil no Brasil. Destes, $30,8 \%$ trabalham sem carteira assinada e $41 \%$ trabalham por conta própria. Dados do IBGE, referente ao final da década de 90 , demonstram que a construção civil é responsável por $10,3 \%$ do Produto Interno Bruto nacional e por $6,6 \%$ das ocupações no mercado de trabalho. Além disso, para cada cem empregos diretos, outros duzentos e oitenta e cinco postos de trabalho são abertos em atividades ligadas a este macro setor ${ }^{2}$.

Na construção civil a terceirização já é uma realidade e, além de aumentar as dificuldades de fiscalização por parte dos sindicatos, tem significado precarização, diminuição da renda dos operários e perda dos direitos trabalhistas historicamente adquiridos.

Em João Pessoa, são aproximadamente 13 mil trabalhadores na construção civil $^{3}$. Em muitas obras se observa a existência de uma verdadeira rede de solidariedade, atenuando as dificuldades dos operários que, na grande maioria, provêm do interior do estado da Paraíba. Esses migrantes buscam na capital uma possibilidade de alimentar suas famílias, que seguem a árdua luta no roçado enquanto rezam para que a chuva caia generosa e a pouca terra que têm permita o broto. Longe de suas casas, os "homenspeões" erguem a cidade, constroem bonitos apartamentos para outros e arrancam o suado salário que afugenta a fome e a morte.

Muitos trabalhadores da construção civil, além do salário, buscam alfabetizar-se através do Projeto Escola Zé Peão. Esse Projeto é resultado de uma parceria entre a Universidade Federal da Paraíba/ Programa de Pós-Graduação em Educação e o Sindicato dos Trabalhadores nas Indústrias da Construção e do Mobiliário de João Pessoa, e se caracteriza como um Projeto de extensão. Tem como objetivo primordial promover a escolarização dos operários que traba- 
Iham nesta indústria. Neste processo, faz uso do próprio local de trabalho dos operários (canteiros de obras) como espaço de realização de suas atividades pedagógicas. Entendendo alfabetização como possibilidade de ampliação da compreensão da realidade social por parte do operário via a aquisição da linguagem, da matemática e dos conhecimentos gerais $\mathrm{e}$ tendo em vista sua melhor capacitação para a reivindicação de seus direitos enquanto trabalhador e cidadão, o Projeto Escola Zé

Peão busca alfabetizar

o maior número possível dos trabalhadores da construção civil. Em onze anos de atividade aproximadamente três mil e cem operários foram alfabetizados ${ }^{4}$.

Esse Projeto foi criado em 1990, por meio de um dissídio coletivo da categoria que assegura que, em alojamentos com mais de 20 trabalhadores é obrigatória a instalação de salas de aulas destinadas aos operários-alunos. Esta cláusula, conquistada em novembro de 1990, tem sido mesmo efetivada na prática nos locais onde a Escola passou a ser assumida enquanto uma necessidade de extrema relevâncias'.

Os alunos-operários que freqüentam a Escola Zé Peão, são trabalhadores da construção civil de João Pessoa, em sua maioria homens ${ }^{6}$, cuja idade varia entre 18 e 55 anos, dos quais a maior parte deles tem origem rural. Muitos moram na periferia da Grande João Pessoa, outros permanecem durante toda a semana alojados no canteiro da obra onde trabaIham, só retornando para as suas cidades de origem, para junto de suas famílias, no final de semana, no período entre oito a quinze dias.

$\mathrm{O}$ índice de analfabetismo que assola a categoria é muito alto. Isto se deve, por um lado, pelo grande número de migrantes rurais que não tiveram a oportunidade de freqüentar escolas. Por outro lado, a natureza instável da indústria da construção civil, o caráter temporário de uma obra, o alto nível de rotatividade que não se registra em outros setores da economia urbana e o uso intensivo da mão-de-obra não qualificada, acaba por dificultar a inserção do trabalhador nos programas oficiais de educação de jovens e adultos. Por isso, a população analfabeta de operários da indústria da construção civil se concentra, particularmente, entre os serventes migrantes vindos do campo: os migrantes temporários ou sazonais que daí procedem, freqüentemente chegam a mais de $60 \%$ da força de trabalho em qualquer obra?. Dada a sua ligação temporária com a indústria e a cidade, são eles, predominantemente, os ocupantes dos alojamentos nos canteiros de obra, não por opção, mas por força da inviabilidade econômica de outras alternativas. A Escola visa atender principalmente este segmento social e educacionalmente mais discriminado da categoria. E foi, precisamente, entre es- ses trabalhadores migrantes que pudemos observar a existência de um grande número de pequenas redes de solidariedade ${ }^{x}$.

\section{AS REDES DE SOLIDARIEDADE}

Basicamente, existe um primeiro migrante que se arrisca em uma nova empreitada. Na construção civil não é diferente. Um migrante, como Benedito, deixa seu município e sua gente e vai tentar a sorte na capital. Encontra emprego como pedreiro. Depois de algum tempo surgem novas vagas que serão preenchidas por novos trabalhadores, contactados através dos próprios migrantes. Não encontramos, na construção civil, alguém que caça trabalhadores, a exemplo do gato na cana-de-açúcar. Esse papel, redimensionado, acaba sendo feito pela boca do próprio operário que, ao voltar para junto dos seus, fala do surgimento de novas vagas, com o principal interesse de ajudar um vizinho, um amigo, um parente.

Essa rede acaba facilitando a vida de muitos trabalhadores que não sabem escrever. A simples tarefa de preencher uma 
ficha pode excluir alguns de um novo emprego. Mas, quando vêm indicados por um conterrâneo, para trabalhar na mesma obra, não necessitam preencher uma ficha, que é substituída pelo conhecimento, pela indicação e pela confiança que outro trabalhador já adquiriu na obra. Quem vem, já vem com a vaga certa e não precisará passar pela torturante etapa de cadastramento e de espera ${ }^{9}$.

Josafá Juvino da Rocha, 45 anos, morador do Sítio Ilha Grande, da cidade de Juazeirinho, interior da Paraíba, explica melhor esse processo de conseguir uma vaga: "A gente pega conhecimento, aí quando abre uma vaga a gente diz: tem meu sobrinho que está parado, tem meu irmão que está parado, vou trazer eles pra trabalhar. Aí eles vêm, começam a trabalhar e a gente fica tudo junto, morando no mesmo lugar".

Assim, com o tempo, o número de conterrâneos vai crescendo, na mesma obra, no mesmo canteiro. Encontramos, por exemplo, em um canteiro com cinqüenta e nove operários-alunos, onze do município de Juarez Távora. Em outro canteiro, com sessenta trabalhadores, quatorze do município de Juazeirinho e dez de Alagoa Grande. Outros seis trabalhadores de Alagoa Grande estão em outro canteiro de vinte e nove operários. Esta subdivisão da rede se repete com doze trabalhadores de Alagoinha, divididos sete em um canteiro e outros cinco em outro, o que chama a atenção e aponta para o fato de que a existência da rede, além da mesma procedência, requer outros elementos como parentesco. compadrio, amizade.

Dentro do mesmo canteiro a existência dessa rede será muito útil aos migrantes. A intimidade existente entre eles permitirá uma organização distinta em relação aos outros trabalhadores. Isso se pode captar com certa facilidade, ainda que tudo esteja presente de forma dissimulada. Senão vejamos, na fala de um deles sobre o fato de serem todos do mesmo município: "é bom, porque a gente tem o que conversar. Não é como desconhecido, a gente confia mais, por ser tudo meio família, tudo do mesmo lugar".
Isso cria um clima de confiança, de fidelidade, facilitando até a articulação na luta e reivindicação pelos direitos. Em vez de cada um fazer sua comida, como normalmente acontece, fazem um revezamento diário ou semanal e um cozinha para todos. Outro gesto que mostra a solidariedade é quanto à feira: a comida que cada um traz de casa ou compra no mercado acaba sendo colocada numa despensa comum, para servir a todos. Essa mesma solidariedade acontece na limpeza do ambiente, no lavar dos pratos, no levar notícias para a família. Nesse caso, a confiança permite que um migrante que porventura não possa ir à sua casa, envie por meio de um amigo ou parente o suado dinheiro para a feira quinzenal da família que está no interior.

Assim, as redes possibilitam uma melhoria significativa na convivência dentro de um alojamento. Ao dividirem as tarefas e responsabilidades estes migrantes encontram mais tempo para o estudo ou para o descanso. Ao criarem um ambiente de confiança, partilham sentimentos, constroem uma identidade mais coletiva. Desta forma, saem do isolamento e constituem uma maior relação social.

A Escola, à noite, mesmo depois de um dia inteiro de trabalho árduo, acaba sendo um lugar de socialização. Dos já mencionados quatorze trabalhadores de Juazeirinho, todos estão estudando, o que só é compreensível pela cumplicidade existente entre eles. Nosso amigo Josafá nos explica: "Um vai e anima o outro: rapaz, vamos estudar; que a gente estudando vai desenrolando mais, melhorando mais".

Essa relação existente entre os trabalhadores desencadeia uma série de novos compromissos de cada um para com todo o grupo.

É nessa perspectiva, de ampliação e potencialização das redes de solidariedade entre os migrantes-alunos-operários, que o Projeto Escola Zé Peão se interpõe.

" Arivaldo J. Sezyshta é padre Escalabriniano e um dos coordenadores do Serviço Pastoral dos Migrantes da Paraiba.
**V Verônica Pessoa é mestranda em Educação Popular pela UFPB e uma das coordenadoras do Projeto Escola Zé Peão.

\section{NOTAS}

1. Este texto foi originalmente criado por Maria de Lourdes Barreto de Oliveira. Para este nosso artigo fizemos algumas alterações e elaboramos algumas estrofes a mais, que estăo inseridas no texto original. Para distinguir, usamos aspas no texto de Maria de Lourdes.

2. Estes dados são do Sindicato das Indústrias da Construção Civil do Estado de São Paulo.

3. Destes 13 mil, aproximadamente 10 mil são os trabalhadores permanentes da construção civil. Cerca de 3 mil são trabalhadores temporários, terceirizados, que estăo na construçăo civil por um tempo, mas acabam trocando de trabaIho com muita freqüência. $O$ número que o $\mathrm{Sin}$ dicato acompanha é de aproximadamente $7 \mathrm{mil}$ trabalhadores na grande João Pessoa.

4. Esse número foi obtido a partir da soma das matriculas efetuadas. Há que se descontar o número de desistências, que são baixas, e outros que acabam freqüentando o projeto por mais de um ano.

5. O texto original, aprovado desde novembro/ 94 consta do seguinte:

"CLÁUSULA DÉCIMA OITAVA - DA EDUCAÇĀO BÁSICA DO TRABALHADOR"

Nos canteiros de obras com mais de 20 (vinte) trabalhadores alojados, as empresas de construção civil se obrigam, dentro dos 60 (sessenta) dias contados a partir da assinatura do presente acordo, a implantar cursos de alfabetização no canteiro de obra, ministrado pelo Sindicato Laboral, após o término do horário de trabalho do segundo turno, cabendo à empresa fornecer as condiçōes mínimas necessárias à viabilizaçāo daquelas aulas.

Parágrafo único: Os operários alunos serāo dispensados do serăo, quando houver".

6. Algumas mulheres que trabalham em empregos domésticos na orla marítima de João Pessoa também estudam na Escola Zé Peão.

7. De 84 entrevistados, 56 vieram do campo, o que nos dá um percentual de $66.6 \%$.

8. Năo nos parece adequada essa terminologia pequenas redes de solidariedade. O termo pequenas é usado aqui em comparação com outras redes maiores, existente, por exemplo, entre os migrantes do interior da Paraíba que, agrupados pelo gato aventuram-se no corte da canade-açúcar na Zona da Mata de Pernambuco ou no distante estado do Maranhăo. Há, ainda, uma rede maior e mais perceptivel entre os migrantes redeiros, que, por cinco ou seis meses, deixam o sertäo para vender as famosas redes paraibanas no sul ou sudeste do Brasil.

9. Freqũentemente migrantes preenchem fichas para trabalhar na construção civil e têm que esperar meses seguidos para serem chamados. Há casos, inclusive, de alguém que preencheu a ficha e acabou perdendo a vaga para outro que veio por indicação de um trabalhador que já estava há algum tempo na obra. 